\title{
Experiences of intimate-partner violence and contraception use among ever-married women in Jordan
}

K. O'Hara, ${ }^{\text {L.C. C. Tsai, }}{ }^{1}$ C.E. Carlson ${ }^{7}$ and Y.M. Haidar'

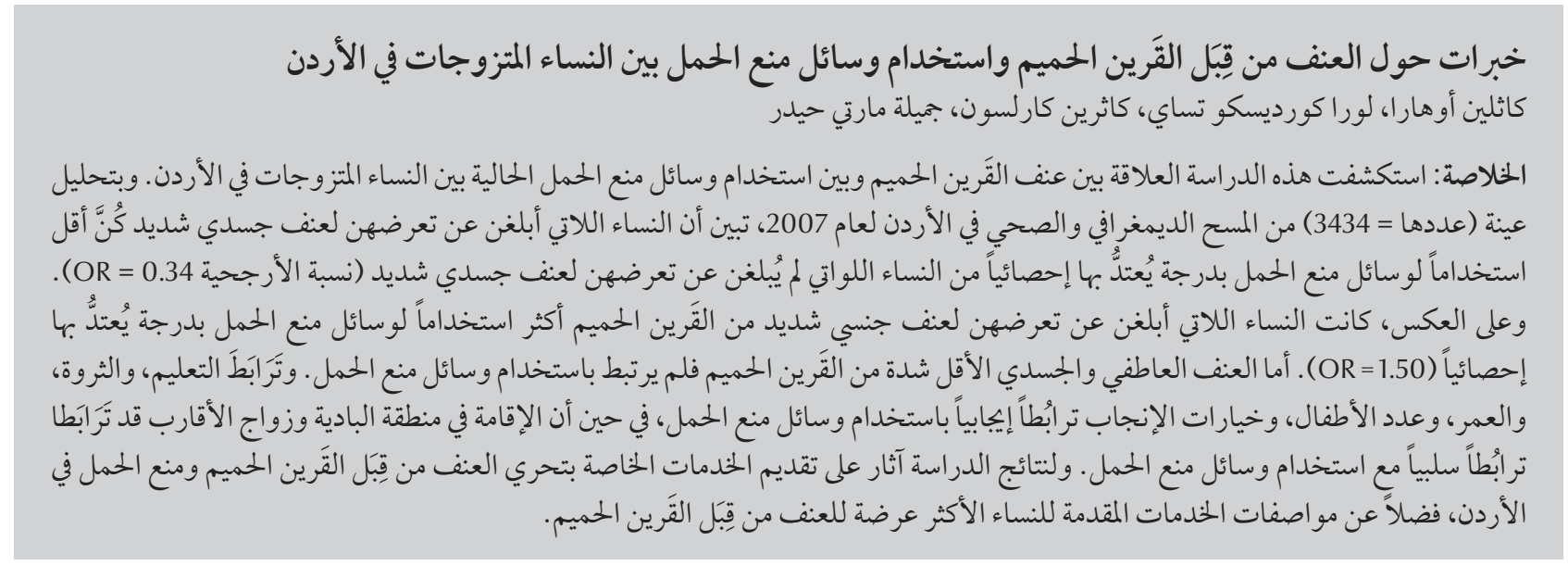

ABSTRACT This study explored the relationship between intimate partner violence (IPV) and current contraception use among ever-married women in Jordan. Analysing a sample $(n=3434)$ from the 2007 Jordan demographic and health survey, women who reported ever experiencing severe physical violence from their husband were significantly less likely to use contraception than women who did not report severe physical violence $(O R=0.34)$. Conversely, women who reported ever experiencing sexual IPV were significantly more likely to use contraception $(O R=1.50)$. Emotional and less severe physical IPV were not significantly related to contraception use. Education, wealth, age, number of children, and fertility preferences were positively associated with contraception use, while residence in the Badia area and consanguineous marriages were negatively associated with contraception use. The findings have implications for the provision of IPV screening and contraception services in Jordan, as well as the specification of services for women most vulnerable to IPV.

Expériences de violence exercée par un partenaire intime et recours à la contraception chez des femmes mariées ou l'ayant déjà été en Jordanie

RÉSUMÉ La présente étude a évalué la relation entre la violence exercée par un partenaire intime et l'utilisation courante de la contraception chez des femmes mariées ou l'ayant déjà été en Jordanie. D'après l'analyse d'un échantillon ( $n=3434)$ de l'Enquête démographique et de santé menée en Jordanie en 2007, les femmes déclarant avoir déjà subi une forme de violence physique grave exercée par leur mari avaient nettement moins tendance à avoir recours à la contraception que les femmes exemptes de violence physique grave $(O . R .=0,34)$. En revanche, les femmes ayant déclaré avoir déjà souffert de violence sexuelle de la part de leur partenaire intime étaient significativement plus susceptibles d'utiliser un mode de contraception (O.R. =1,50). La violence psychologique ainsi que la violence physique de gravité moindre exercées par un partenaire intime n'étaient pas significativement liées au recours à la contraception. Le niveau d'études, le revenu, l'âge, le nombre d'enfants et les préférences en matière de fécondité étaient des éléments positivement associés à l'utilisation de la contraception, alors qu'une résidence dans la région de Badia et des mariages consanguins étaient négativement associés au recours à la contraception. Ces résultats ont des conséquences sur l'offre de services de contraception et le dépistage de la violence exercée par le partenaire intime en Jordanie, ainsi que pour le contenu des services destinés aux femmes les plus vulnérables à la violence de leur partenaire intime. 


\section{Introduction}

Intimate partner violence (IPV) has been shown to adversely affect numerous health outcomes for women, including dimensions of physical, psychosocial and sexual health $[1,2]$. Specific to women's sexual health, Coker has drawn on the World Health Organization's (WHO) definition of wellbeing to conceptualize IPV as impacting both health outcomes and women's ability to make beneficial health choices [3]. While the evidence base generally confirms a negative relationship between IPV and sexual health outcomes [3-5], women in Jordan present a complex relationship between IPV and one aspect of sexual health choice, that of contraception use.

In Jordan, 30\% of married women and up to $87 \%$ of married women in selected governorates have reported experiencing IPV in their lifetime [6,7]. Additionally, $97 \%$ of married women surveyed in Amman had experienced controlling behaviour by their spouse [8], a phenomenon positively associated with IPV $[2,9]$. These IPV rates echo a high regional prevalence of IPV [10] and are high in comparison with rates cited in a seminal WHO study that found between $15 \%$ to $71 \%$ of women in participating nations had experienced IPV in their lifetime [2].

Jordanian women, however, also reported high rates of female contraception use, a sexual health outcome that has steadily improved since the federal government implemented the National Birth Spacing Programme in $1996[7,11]$. Nationally, 56\% of women of childbearing age currently use contraception, $81 \%$ of women have ever used contraception and 99\% of women know of at least one contraception method. In a 35-country survey, Jordan's $81 \%$ rate of ever use of contraception compared favourably to other national rates between $17 \%$ and $96 \%[12]$.
In response to the high prevalence of both phenomena, this study explored the association between ever experiencing IPV and current contraception use among ever-married women in Jordan. The global literature has established significant associations between IPV and contraception use, though these have been found to be both positive $[2,13,14]$ and negative $[15-17]$. Previous research in Jordan has demonstrated a negative association between IPV and contraception use $[6,8]$. Additionally, studies that disaggregated forms of IPV have found unique associations between these distinct forms of violence and contraception use $[3,13,17]$. In response to these divergent findings, we hypothesized that there would be a significant association between ever experiencing IPV and current contraception use in Jordan, and that the association was unique among distinct forms of IPV.

\section{Methods}

\section{Study design}

The present study was based on secondary analysis of data from the 2007 demographic and health survey in Jordan, the Jordan Population and Family Health Survey (JPFHS) — individual woman section [7]. Because this study was based on a publicly available dataset, institutional review board approval was not sought.

\section{Sample}

The JPFHS encompassed a nationally representative sample of ever-married women in Jordan aged 15-49 years. The domestic violence module was administered to one-third of the total JPFHS sample, chosen at random using a probability weight. A detailed description of JPFHS stratified sampling strategies, including protocols to reduce the unintended consequences of participation, is reported elsewhere [7]. The JPFHS was developed in Arabic and English, and incorporates 8 topic areas, including fertility, family planning and domestic violence. The domestic violence module instrument was based on the Revised Conflict Tactics Scale [18] and asks only about IPV perpetrated by the woman's husband.

Although a total of 10876 women participated in the survey, only a purposive sub-sample of JPFHS participants were invited to complete the domestic violence survey module. This domestic violence sub-sample included 3444 women; after removing 10 women with missing values, we based this study on the remaining 3434 women.

\section{Data collection}

Drawing on the JPFHS domestic violence survey categories, we defined the independent variable in terms of 4 distinct forms of IPV: 1) sexual violence: the use of coercion to engage a partner in sexual acts against her will; 2) severe physical violence: including choking, threatening and attacking with a knife, gun or other weapon; 3) less severe physical violence: pushing, slapping or punching or throwing objects; and 4) emotional violence: humiliating, insulting and threatening. The dependent variable was current use of any form of contraception, including both modern (e.g. intrauterine device) and traditional (e.g. withdrawal) forms.

\section{Data analysis}

Analysis was conducted using Stata/IC, version 11.0. We used the chi-squared test of independence to compare the percentage of women who used/did not use contraception by relevant sociodemographic characteristics and types of IPV experienced. Two logistic regression models were used to examine the relationship between ever experiencing IPV and current contraception use. In the first regression, IPV was aggregated to include all measured forms of violence. In the second logistic regression, IPV was disaggregated into 4 categories: sexual, severe physical, less severe 
physical and emotional violence. Some sampled individuals experienced more than 1 type of IPV; to verify that overlap among different types of IPV did not affect the outcomes of the second model, we conducted 4 additional logistic regressions, each of which included just 1 type of IPV as the sole independent variable. Given that each of these additional models resulted in similar findings, we did not include those results in the manuscript. The analysis controlled for the following covariates: respondent's age; marital status; education level; wealth index; employment status; number of children; current sexual activity; desire to conceive children; desired number of children as compared to her husband's desired number of children; husband's level of education; husband's approval of contraception use; knowledge of sexually transmitted infections (STI); in a consanguineous marriage or not; and infertile/menopausal or not. Analysis also controlled for rural versus urban residence and Badia versus non-Badia residence. The Badia is a rural area in north-eastern Jordan that is home to the Bedouins; the Bedouins tend to be more socially conservative than other Jordanians and contraception use is less prevalent among women in this area [19]. Whether or not the respondent had menstruated within the past 3 months was used as a proxy for pregnancy. All tests were 2-tailed, with significance judged at the 0.05 level.

\section{Results}

The sociodemographic characteristics of the study women and their current use of contraception are shown in Table 1. Slightly more than half ( $52.4 \%)$ of women in the sample reported currently using contraception. A chi-squared test of independence indicated that the likelihood of women's current contraception use differed significantly based on their age $(P<0.001)$, marital status $(P$

\begin{tabular}{|c|c|c|c|c|}
\hline \multirow[t]{3}{*}{ Characteristic } & \multicolumn{2}{|c|}{$\begin{array}{l}\text { Woman currently using } \\
\text { contraception }\end{array}$} & \multirow[t]{2}{*}{ Total } & \multirow[t]{2}{*}{$P$-value } \\
\hline & $\begin{array}{c}\text { Yes } \\
(n=1861)\end{array}$ & $\begin{array}{c}\text { No } \\
(n=1583)\end{array}$ & & \\
\hline & $\%$ & $\%$ & $\%$ & \\
\hline Total & 52.4 & 47.6 & & \\
\hline Age (years) & & & & $<0.001$ \\
\hline $15-19$ & 0.7 & 2.1 & 1.3 & \\
\hline $20-24$ & 8.5 & 14.3 & 11.2 & \\
\hline $25-29$ & 17.4 & 20.3 & 18.8 & \\
\hline $30-34$ & 22.1 & 18.0 & 20.6 & \\
\hline $35-39$ & 22.1 & 18.0 & 20.2 & \\
\hline $40-44$ & 19.0 & 14.9 & 17.1 & \\
\hline $45-49$ & 9.4 & 12.4 & 10.8 & \\
\hline Marital status & & & & $<0.001$ \\
\hline Married & 99.4 & 90.9 & 95.5 & \\
\hline Not married & 0.6 & 9.1 & 4.5 & \\
\hline Badia resident & & & & $<0.001$ \\
\hline Yes & 88.5 & 83.2 & 86.1 & \\
\hline Not & 11.5 & 16.7 & 13.9 & \\
\hline Woman's education & & & & $<0.001$ \\
\hline None & 4.2 & 8.8 & 6.3 & \\
\hline Primary & 64.5 & 64.5 & 64.9 & \\
\hline Secondary & 30.6 & 25.0 & 28.0 & \\
\hline Higher & 0.8 & 0.7 & 0.7 & \\
\hline Husband's education & & & & $<0.001$ \\
\hline None & 2.4 & 5.1 & 3.7 & \\
\hline Primary & 11.8 & 15.4 & 13.4 & \\
\hline Secondary & 58.6 & 58.5 & 58.6 & \\
\hline Higher & 27.1 & 20.8 & 24.2 & \\
\hline Wealth index & & & & $<0.001$ \\
\hline Poorest & 22.6 & 32.2 & 27.0 & \\
\hline Poor & 24.3 & 28.0 & 26.0 & \\
\hline Middle & 22.4 & 18.1 & 20.4 & \\
\hline Rich & 18.3 & 14.0 & 16.3 & \\
\hline Richest & 7.8 & 12.4 & 10.3 & \\
\hline Currently working & & & & 0.071 \\
\hline Yes & 15.1 & 13.0 & 14.1 & \\
\hline No & 84.9 & 87.1 & 85.9 & \\
\hline No. of children & & & & $<0.001$ \\
\hline 0 & 0.3 & 16.8 & 7.9 & \\
\hline $1-3$ & 36.0 & 42.8 & 39.1 & \\
\hline $4-6$ & 44.8 & 27.0 & 36.6 & \\
\hline $7+$ & 18.9 & 13.4 & 16.4 & \\
\hline
\end{tabular}

${ }^{a}$ Chi-squared test of independence. 
$<0.001)$, Badia or non-Badia residency $(P<0.001)$, education $(P<0.001)$, husband's education, wealth $(P<0.001)$ and number of children $(P<0.001)$. There was no statistically significant difference in contraception use between women who were currently working and not currently working $(P=0.071)$.

Exploratory data analysis revealed that approximately $30 \%$ of the domestic violence sub-sample reported ever experiencing at least 1 form of IPV. The prevalence of each type of violence was: less severe physical (19.6\%), emotional (18.7\%), sexual (8.5\%) and severe physi$\mathrm{cal}(1.3 \%)$. Chi-squared tests of independence demonstrated that women were less likely to report currently using contraception if they reported experiencing severe physical violence $(P=0.005)$, less severe physical violence $(P=0.074)$ or emotional violence $(P=0.035)$ compared with women who did not report experiencing 1 of those types of violence (Table 2). We found no significant difference in current contraception use among women who reported experiencing sexual violence $(P=0.258)$.

The results of the first logistic regression are shown in Table 3. The analysis was conducted while controlling for respondents': age; marital status; education level; wealth index; employment status; number of children; knowledge about sexually transmitted infections (STI); rural versus urban residence; Badia versus non-Badia residence; desired children or not; currently sexually active or not; in consanguineous marriage or not, infertile/menopausal or not; husband's level of education; and husband's approval of contraception use. The analysis also controlled for whether the husband wanted more children or less children than the respondent (versus the same number of children). Whether or not the respondent had menstruated within the past 3 months was used as a proxy for pregnancy. The results indicated that ever experiencing any kind of IPV showed no significant relationship with current contraception use $(\mathrm{OR}=1.10$; 95\% CI: 0.91-1.33) (Table 3). However, the results of the second logistic regression revealed that the association between ever experiencing IPV and current contraception use varied according to type of violence. The odds that women would use contraception were on average lower for those who reported experiencing severe physical violence compared with women who did not (OR $=0.34 ; 95 \%$ CI: 0.14-0.82) (Table 3). Conversely, all else being equal, the odds of currently using contraception were greater for women who reported experiencing sexual violence compared with those who did not $(\mathrm{OR}=1.50 ; 95 \% \mathrm{CI}$ : 1.06-2.11). Emotional violence and less severe physical violence did not have a significant relationship with current contraception use. A zero-order correlation matrix showed Pearson $r$ values ranging from 0.0003 to 0.64 , demonstrating that multicollinearity was not a problem.

Some covariates included in the logistic regression models were significant predictors of contraception use. Compared with having no education, completion of secondary school $(\mathrm{OR}=2.46$; 95\% CI 1.60-3.76) and completion of higher education $(\mathrm{OR}=3.04 ; 95 \% \mathrm{CI}$ : 1.88-4.91) were significant predictors of contraception use among the study women (Table 3). Women in the rich $(\mathrm{OR}=1.45 ; 95 \% \mathrm{CI}: 1.08-1.95)$ and richest wealth indices $(\mathrm{OR}=1.81 ; 95 \%$ CI: $1.26-2.60)$ were significantly more likely to use contraception when compared with the poorest wealth index. Number of children ( $\mathrm{OR}=1.48 ; 95 \% \mathrm{CI}$ : $1.40-1.57)$, sexual activity in the past 3 months (OR $=4.38$; 95\% CI: 3.12-6.14), menstruation in the past 3 months (OR $=0.11 ; 95 \%$ CI: $0.08-0.13)$, residence outside Badia area $(\mathrm{OR}=1.32$; 95\% CI: 1.01-1.73) and husband's approval of contraception (OR $=5.07 ; 95 \% \mathrm{CI}$ : 3.78-6.82) were all significant predictors of contraception use. The husband's wanting more children than the wife did (compared with wanting the same number of children as the wife) $(\mathrm{OR}=0.80$; 95\% CI: 0.64-0.99) and the woman not wanting children in the next 2 years (OR $=1.99$; $95 \%$ CI: $1.60-2.46)$ were also significant predictors of contraception use.

\section{Discussion}

This study has made an early contribution to research on the relationship between IPV and contraception use among ever-married Jordanian women. Although no significant association

\begin{tabular}{|c|c|c|c|c|}
\hline \multirow[t]{3}{*}{ Variable } & \multicolumn{2}{|c|}{ Woman currently using contraception } & \multirow[t]{2}{*}{ Total } & \multirow[t]{3}{*}{$P$-value ${ }^{\text {a }}$} \\
\hline & $\begin{array}{c}\text { Yes } \\
(n=1861)\end{array}$ & $\begin{array}{c}\text { No } \\
(n=1583)\end{array}$ & & \\
\hline & $\%$ & $\%$ & $\%$ & \\
\hline Any IPV & 28.5 & 29.5 & 29.0 & 0.533 \\
\hline Any sexual violence & 9.0 & 7.9 & 8.5 & 0.258 \\
\hline Any severe physical violence & 0.8 & 1.9 & 1.3 & 0.005 \\
\hline Any less severe physical violence & 18.5 & 20.9 & 19.6 & 0.074 \\
\hline Any emotional violence & 17.4 & 20.2 & 18.7 & 0.035 \\
\hline
\end{tabular}

a $P$-value for chi-squared test of independence. 


\begin{tabular}{|c|c|c|c|c|c|c|c|c|}
\hline \multirow[t]{2}{*}{ Variable } & \multicolumn{4}{|c|}{ Model 1} & \multicolumn{4}{|c|}{ Model 2} \\
\hline & OR & SE & $\mathbf{z}$ & $95 \% \mathrm{Cl}$ & OR & SE & $\mathbf{z}$ & $95 \% \mathrm{Cl}$ \\
\hline $\begin{array}{l}\text { Any intimate partner } \\
\text { violence }\end{array}$ & 1.10 & 0.11 & 0.97 & $0.91-1.33$ & - & - & - & - \\
\hline Any sexual violence & - & - & - & - & $1.50^{*}$ & 0.26 & 2.29 & $1.06-2.11$ \\
\hline $\begin{array}{l}\text { Any severe physical } \\
\text { violence }\end{array}$ & - & - & - & - & $0.34^{*}$ & 0.15 & -2.39 & $0.14-0.82$ \\
\hline $\begin{array}{l}\text { Any less severe physical } \\
\text { violence }\end{array}$ & - & - & - & - & 0.93 & 0.12 & -0.52 & $0.72-1.21$ \\
\hline Any emotional violence & - & - & - & - & 1.09 & 0.14 & 0.67 & $0.84-1.41$ \\
\hline Age & $1.13^{*}$ & 0.06 & 2.53 & $1.03-1.25$ & $1.14^{*}$ & 0.06 & 2.55 & $1.03-1.25$ \\
\hline Age squared & $1.00^{* * *}$ & 0.00 & -3.59 & $1.00-1.00$ & $1.00^{* * *}$ & 0.00 & -3.97 & $1.00-1.00$ \\
\hline Marriage & 0.91 & 0.37 & -0.24 & $0.41-2.00$ & 0.89 & 0.36 & -0.29 & $0.40-1.97$ \\
\hline $\begin{array}{l}\text { Primary education } \\
\text { completed }\end{array}$ & 1.48 & 0.36 & 1.62 & $0.92-2.38$ & 1.46 & 0.35 & 1.55 & $0.90-2.34$ \\
\hline $\begin{array}{l}\text { Secondary education } \\
\text { completed }\end{array}$ & $2.46^{* * *}$ & 0.53 & 4.13 & $1.60-3.76$ & $2.45^{* * *}$ & 0.54 & 4.10 & $1.60-3.76$ \\
\hline $\begin{array}{l}\text { Higher education } \\
\text { completed }\end{array}$ & $3.04^{* * *}$ & 0.75 & 4.52 & $1.88-4.91$ & $3.00^{* * *}$ & 0.74 & 4.47 & $1.86-4.87$ \\
\hline $\begin{array}{l}\text { Husband's education } \\
\text { level }\end{array}$ & 1.02 & 0.08 & 0.21 & $0.88-1.18$ & 1.02 & 0.08 & 0.23 & 0.88-1.18 \\
\hline Lowest income level & 0.94 & 0.11 & -0.54 & $0.74-1.19$ & 0.94 & 0.11 & -0.55 & 0.74-1.19 \\
\hline Middle income level & 1.14 & 0.15 & 0.95 & $0.88-1.47$ & 1.13 & 0.15 & 0.92 & $0.87-1.47$ \\
\hline High income level & $1.45^{*}$ & 0.22 & 2.47 & $1.08-1.95$ & $1.46^{*}$ & 0.22 & 2.49 & $1.08-1.96$ \\
\hline Highest income level & $1.81^{* *}$ & 0.34 & 3.20 & $1.26-2.60$ & $1.82^{* *}$ & 0.34 & 3.23 & $1.27-2.63$ \\
\hline Working outside home & 1.12 & 0.16 & 0.79 & $0.85-1.48$ & 1.13 & 0.16 & 0.87 & 0.86-1.49 \\
\hline Number of children & $1.48^{* * *}$ & 0.04 & 13.99 & $1.40-1.57$ & $1.49^{* * *}$ & 0.04 & 13.98 & $1.41-1.57$ \\
\hline $\begin{array}{l}\text { Husband wants more } \\
\text { children }\end{array}$ & $0.80^{*}$ & 0.09 & -2.06 & $0.64-0.99$ & $0.80^{*}$ & 0.09 & -2.09 & $0.64-0.99$ \\
\hline $\begin{array}{l}\text { Husband wants less } \\
\text { children }\end{array}$ & 0.85 & 0.12 & -1.15 & $0.64-1.13$ & 0.85 & 0.12 & -1.15 & $0.64-1.13$ \\
\hline $\begin{array}{l}\text { Unsure of husband's child } \\
\text { preferences }\end{array}$ & 1.59 & 0.40 & 1.85 & $0.97-2.62$ & $1.65^{*}$ & 0.42 & 1.97 & $1.00-2.70$ \\
\hline $\begin{array}{l}\text { Wife not wanting children } \\
\text { in next } 2 \text { years }\end{array}$ & $1.99 * * *$ & 0.22 & 6.28 & $1.60-2.46$ & $2.01^{* * *}$ & 0.22 & 6.37 & $1.62-2.49$ \\
\hline Infertility & $0.06^{* *}$ & 0.06 & -2.73 & $0.01-0.44$ & $0.05^{* *}$ & 0.06 & -2.75 & $0.01-0.43$ \\
\hline Recent sexual activity & $4.38^{* * *}$ & 0.76 & 8.56 & $3.12-6.14$ & $4.41^{* * *}$ & 0.76 & 8.57 & $3.14-6.20$ \\
\hline Consanguinity & 1.17 & 0.10 & 1.80 & 0.99-1.39 & 1.18 & 0.11 & 1.88 & $0.99-1.40$ \\
\hline STI diagnosis & 0.94 & 0.32 & -0.19 & $0.48-1.83$ & 0.95 & 0.32 & -0.16 & $0.48-1.85$ \\
\hline Rural or urban residence & 0.92 & 0.09 & -0.82 & $0.75-1.12$ & 0.92 & 0.09 & -0.77 & $0.76-1.13$ \\
\hline Badia residence & $1.32^{*}$ & 0.18 & 2.03 & $1.01-1.73$ & $1.33^{*}$ & 0.18 & 2.08 & $1.02-1.75$ \\
\hline Experiencing menopause & 0.68 & 0.35 & -0.74 & $0.25-1.88$ & 0.68 & 0.35 & -0.74 & $0.25-1.87$ \\
\hline $\begin{array}{l}\text { No menstruation in last } 3 \\
\text { months }\end{array}$ & $0.11^{* * *}$ & 0.01 & -19.16 & $0.08-0.13$ & $0.11^{* * *}$ & 0.01 & -19.17 & $0.84-0.13$ \\
\hline $\begin{array}{l}\text { Husband approves of } \\
\text { contraception }\end{array}$ & $5.07^{* * *}$ & 0.76 & 10.77 & $3.78-6.82$ & $5.04^{* * *}$ & 0.76 & 10.68 & $3.75-6.78$ \\
\hline
\end{tabular}

${ }^{*} P<0.05$; ${ }^{*} P<0.01$; ${ }^{* *} P<0.001$.

$S T I=$ sexually transmitted infection.

$O R=$ odds ratio; $C I=$ confidence interval; $S E=$ standard error 
was found between women's experiencing any form of IPV and current contraception use, the association between distinct forms of violence and current contraception use varied in significance, strength and direction, as consistent with our hypothesis. The variation between aggregated and disaggregated violence, coupled with variations among distinct types of violence, illuminates the truly complex relationship between IPV and contraception use. For example, capturing a simple directional association between IPV and contraception use may belie a nuanced series of factors and processes that impact this relationship. Studies spanning multiple nations have found that women who have recently experienced IPV were more likely to have attempted to use contraception and/ or ask their partners to use a condom, but they were also more likely to report partner interference with contraception use $[2,14]$.

Women who reported ever experiencing severe physical violence had on average significantly lower odds of currently using contraception $(\mathrm{OR}=$ 0.34). This finding echoes the majority of reviewed studies exploring IPV and contraception use $[5,6,8,16,17]$. These studies, together with further analysis of data from this study (published elsewhere) suggest that a woman experiencing severe physical violence may have (or have had) a husband who uses multiple forms of violence to dominate all aspects of the spousal relationship, including contraception use.

Women who reported ever experiencing sexual violence were on average significantly more likely to currently use contraception $(\mathrm{OR}=1.50)$. While this finding contrasts with many previous studies, including those in Jordan $[6,8]$, it adds to a growing body of international literature that demonstrates a positive association between IPV and female contraception use $[13,14]$. Additionally, among previous studies that disaggregated types of IPV, there was evidence from sub-Saharan Africa that sexual violence was positively associated with contraception use [13]. Sexual violence may be the form of IPV with the greatest potential to impact a woman's desire to use contraception, in that each act of violence has the potential to result in unplanned pregnancy and/or HIV/STIs. Women in violent relationships have described abusive partners' indifference to and/or sabotage of both male and female contraception methods, leaving the woman vulnerable to pregnancy and infection if they are not able to devise a way to continue to use contraception [20]. Further, research suggests pregnancy is not a safeguard against violence, and in fact may escalate violence and/ or a husband's control over his wife $[3,9,16,20]$. Thus, Jordanian women who experience this form of violence may have an increased incentive to use contraception to safeguard their sexual health and overall wellbeing.

Some study limitations deserve consideration. A general challenge of secondary data analysis is the inability to influence the content of the data collection instrument. The JPFHS instrument was not designed to measure the larger social or cultural environment in which health outcomes are situated, and therefore a potential limitation of this study is the absence of broader social constructs that may be relevant to the present models, such as religiosity and normative roles for women. Additionally, we were unable to include some potentially relevant covariates in our regression models due to hierarchical survey question ordering. For example, previous studies in both Jordan and international settings have found that decision-making on contraception use often involves women's male partners as either a dominant or cooperative decision-maker $[21,22]$. While this covariate would have been relevant to our models, the JPFHS measure on contraception decision-making only captured respondents who had reported current contraception use. Because women who reported no current contraception use were not asked about household decision-making about not using contraception, the covariate was excluded from our models.

The present study leads to several recommendations. First, the prevalence of female contraception use in this sample supports the idea that the National Birth Spacing Programme in Jordan has effectively reached many women $[7,11]$ and further, our results demonstrate that this includes many women experiencing sexual violence. Because many Jordanian women use contraception, health-facility staff should consider incorporating IPV screening as a standardized component of female sexual health care. Health facilities may also provide a neutral venue for IPV service providers to gain access to women experiencing violence. While there has been debate on the use of health facilities for IPV screening/intervention, previous research in Jordanian health clinics suggests that when IPV screening is context-specific and culturally sensitive, women in violent relationships are willing to disclose their situation [23]. Jordanian women experiencing severe physical violence deserve special consideration. Service providers should be aware that these women are less likely to be identified via sexual health services, as they are less likely to access contraception. Simultaneously, IPV service providers who already work with women experiencing severe physical violence should be responsive to this group's limited access to contraception, which places them at greater risk for unwanted pregnancy and HIV/STIs. Based on our findings, women possessing certain sociodemographic characteristics should be targeted for IPV and family planning outreach: those of lower educational and socioeconomic status, in consanguineous marriages and living in the Badia region. Given previous research demonstrating Jordanian men's views on family planning were associated with 
female contraception use patterns [21], interventions to change knowledge and behaviours related to family planning should target men as well.

Future research should include more precise measurement and analysis of the impact of distinct and sometimes concurrent forms of IPV on contraception use. More exact temporal measurement of the occurrence of IPV and contraception use is needed to limit the potential for reverse causality. Finally, further qualitative research has the potential to better define the association mechanisms between IPV and female contraception use. In particular,increased attention to the social and cultural environment in Jordan may yield a richer understanding of women's experiences with both IPV and contraception use.

Competing interests: None declared.

\section{References}

1. Heise L, Ellsberg M, Gottmoeller M. A global overview of gender-based violence. International Journal of Gynaecology and Obstetrics, 2002, 78(Suppl. 1):S5-S14.

2. Garcia-Moreno C et al. WHO multi-country study on women's health and domestic violence against women: initial results on prevalence, health outcomes and women's responses. Geneva, World Health Organization, 2005.

3. Coker AL. Does physical intimate partner violence affect sexual health? A systematic review. Trauma, Violence and Abuse, 2007, 8:149-177.

4. García-Moreno C, Stöckl H. Protection of sexual and reproductive health rights: addressing violence against women. International Journal of Gynaecology and Obstetrics, 2009, 106:144-147.

5. Pallitto CC, Campbell JC, O'Campo P. Is intimate partner violence associated with unintended pregnancy? A review of the literature. Trauma, Violence and Abuse, 2005, 6:217-235.

6. Al-Nsour M, Khawaja M, Al-Kayyali G. Domestic violence against women in Jordan: evidence from health clinics. Journal of Family Violence, 2009, 24:569-575.

7. Jordan population and family health survey 2007. Calverton, Maryland, Macro International and Amman, Jordan, Department of Statistics, 2007.

8. Clark CJ et al. Prevalence estimate of intimate partner violence in Jordan. Eastern Mediterranean Health Journal, 2009, 15:880-889.

9. Hindin MJ, Adair LS. Who's at risk? Factors associated with intimate partner violence in the Philippines. Social Science and Medicine, 2002, 55:1385-1399.

10. Boy A, Kulczycki A. What we know about intimate partner violence in the Middle East and North Africa. Violence Against Women, 2008, 14:53-70.

11. Youssef RM. Duration and determinants of interbirth interval: community-based survey of women in southern Jordan. Eastern Mediterranean Health Journal, 2005, 11:559-572.

12. Khan $\mathrm{S}$ et al. Contraceptive trends in developing countries. Calverton, Maryland, Macro International, 2007.
13. Alio AP et al. Intimate partner violence and contraception use among women in Sub-Saharan Africa. International Journal of Gynaecology and Obstetrics, 2009, 107:35-38.

14. Fanslow J et al. Contraceptive use and associations with intimate partner violence among a population-based sample of New Zealand women. Australian and New Zealand Journal of Obstetrics and Gynaecology, 2008, 48:83-89.

15. Ayoola AB, Nettleman M, Brewer J. Reasons for unprotected intercourse in adult women. Journal of Women's Health, 2007, 16:302-310.

16. Diop-Sidibé N, Campbell JC, Becker S. Domestic violence against women in Egypt-wife beating and health outcomes. Social Science and Medicine, 2006, 62:1260-1277.

17. Williams CM, Larsen U, McCloskey LA. Intimate partner violence and women's contraceptive use. Violence Against Women, 2008, 14:1382-1396.

18. Straus MA et al. The Revised Conflict Tactics Scales (CTS2) development and preliminary psychometric data. Journal of Family Issues, 1996, 17:283-316.

19. El-Qaderi SA, Al-Omari N. Knowledge, attitudes and practices of family planning among currently married women in Jordan Badia. International Quarterly of Community Health Education, 2001, 20:171-191.

20. Moore AM, Frohwirth L, Miller E. Male reproductive control of women who have experienced intimate partner violence in the United States. Social Science and Medicine, 2010, 70:17371744.

21. Petro-Nustas W. Men's knowledge of and attitudes towards birth spacing and contraceptive use in Jordan. International Family Planning Perspectives, 1999, 25:181-185.

22. Zhang L. Male fertility patterns and determinants. New York, Springer, 2010.

23. Clark CJ et al. The role of the extended family in women's risk of intimate partner violence in Jordan. Social Science and Medicine, 2010, 70:144-151. 